\title{
LER, ESCREVER, PERDER: PSICANÁLISE E MATHESIS
}

Fernanda Costa-Moura ${ }^{\star}$

\begin{abstract}
Resumo
Partindo da distinção entre ler, escrever e perder como formas de conhecimento (mathesis), proposta por Lacan no seminário $O$ ato psicanalítico, o trabalho discerne a constituição do real e do sujeito em cada uma destas vias de apreensão douta relacionando a primeira à reminiscência, a segunda à ciência e situando a terceira como o próprio da psicanálise. Enfatizando o reviramento efetuado sobre a noção de saber em sua articulação e aproveitamento no campo psicanalítico, conclui-se que a práxis psicanalítica implica necessariamente uma perda que incidirá para o sujeito no nivel de suas relações com o saber e com o ato.
\end{abstract}

Palavras-chave: psicanálise; sujeito; ciência; real; ato.

\section{READ, WRITE, LOOSE: PSYCHOANALYSIS AND MATHESIS}

\begin{abstract}
Starting from the distinction between reading, writing and loosing as forms of knowledge (mathesis), proposed by Lacan in the seminar about the Psychoanalytical act the paper deals with the constitution of the subject and the real relating each of these terms to a specific form of knowledge: reading is related to Plato's Reminiscence theory, writing, to science and loosing to psychoanalysis itself. Emphasizing the subversion suffered by knowledge in it's relation to the psychoanalytical field the article concludes that psychoanalysis implies some extent of loss that will necessarily fall upon the subject's relation to knowledge and act.
\end{abstract}

Keywords: psychoanalysis; subject; science; real; act.

\footnotetext{
^ Psicanalista. Doutora em Psicologia Clínica, Pontifícia Universidade Católica do Rio de Janeiro. Membro do Tempo Freudiano Associação Psicanalítica. Professora do Programa de Pós-Graduação em Teoria Psicanalítica do Instituto de Psicologia-Universidade Federal do Rio de Janeiro. Endereço: Universidade Federal do Rio de Janeiro, Programa de Pós-Graduação em Teoria Psicanalítica. Avenida Pasteur, 250 Fundos. Praia Vermelha. Rio de Janeiro, RJ - Brasil. CEP: 22290-240.

E-mail: fcostamoura@infolink.com.br
} 
- [...] Qual é a primeira coisa de que você se lembra?

- Hum... Deixe ver... A primeira que me vem à cabeça?

- Não, a primeira lembrança que você tem.

- Devo tê-la esquecido.

- Justamente, a primeira que não tenha esquecido.

Longa reflexão...

- Esqueci a pergunta. (STOPPARD, 1991[1967], p. 16) ${ }^{1}$

Lacan inicia a lição de 6 de dezembro do seu seminário de 1967-1968 sobre "O ato psicanalítico" comentando este trecho da comédia absurda e existencialista Rosencrantz e Guildenstern estão mortos de Tom Stoppard (1991[1967]). A peça gira em torno das desventuras de dois personagens secundários do Hamlet de Shakespeare (1992[1599-1601]) que ganham lugar de protagonistas. Enquanto viajam a caminho do castelo de Elsinore, os dois ponderam sobre o sentido de suas existências e expressam sua perturbação em relação ao progresso dos acontecimentos que estando relacionados ao que ocorre na ação de Hamlet enquanto eles não estão em cena, eles não conseguem apreender. Ao discutir temas como livre arbítrio e determinismo, a ausência de valores intrínsecos e a impossibilidade da certeza, a peça mostra os personagens enredados na polissemia da linguagem e sem meios de alcançar qualquer estabilidade.

Rosencrantz e Guildenstern, ao contrário do anunciado, estão bem vivos entre nós. Em Hamlet os dois são "marionetes essenciais à tragédia" (LACAN, 1967-1968, lição de 06/12/67): ora manipulados pelo rei para revelar os planos de Hamlet contra ele, ora presas fáceis do príncipe, que os ludibria e se vinga, arranjando as coisas para que eles morram em seu lugar. Na peça de Stoppard (1991[1967]) são retratados como clowns; alçados a um mundo além de sua compreensão, no qual não podem identificar nenhuma constante que os afiance e muito menos, a significação derradeira das palavras e dos eventos que sucedem. Da perspectiva dos dois, a ação que se desenrola em Hamlet - ação que Lacan qualifica como "a tragédia que é verdadeiramente a nossa própria" (LACAN, 1967-1968, lição de 06/12/67) - é puro nonsense. Equivocando-se o tempo todo e entre si, tropeçando em evidências, sem poder discernir as implicações e a verdade que contêm, eles colocam em xeque a continuidade suposta na estruturação da realidade e em nossa percepção das coisas:

[...]onde foi parar o momento exato em que primeiro tivemos notícia da morte? Deve ter havido um momento, um em especial, na infância, quando pela primeira vez nos ocorreu que não duraríamos para sempre. Deve ter sido demolidor, gravado a ferro na memória. E mesmo assim, não consigo me lembrar. ${ }^{2}$ (STOPPARD, 1991[1967], p. 72)

$\mathrm{O}$ trecho escolhido por Lacan pertence à cena que abre o primeiro ato. Nela figuram os dois companheiros apostando, há já algum tempo, no "cara ou coroa". A cada lance disparado por Guildenstern, Rosencrantz escolhe "cara" e ganha, 91 
vezes seguidas, o jogo. A inverossimilhança de tal evento ocorrer é total, segundo as leis da probabilidade, o que leva Guildenstern a se preocupar não tanto com o dinheiro apostado, mas com as implicações da coisa. Organizando depressa uma lista de possíveis explicações, enumera. A primeira: em seu íntimo, sem saber, ele é um homem jogando moedas de uma face só, apostando contra ele mesmo, tentando reparar um passado do qual ele não se lembra. Atira de novo a moeda e... "cara"! Constata Rosencrantz. Segunda: o tempo parou e a experiência de uma moeda sendo jogada uma vez se repetiu 92 vezes - alternativa a rigor, duvidosa. Terceira: intervenção divina, o que implicaria um Deus que surge de cima e se importa com ele. Quarta: demonstração espetacular do princípio de que cada moeda jogada individualmente tem igual número de chances de cair do lado "cara" ou do lado "coroa" - o que não deve causar surpresa, cada vez que acontece. A cada lance "a sorte foi posta em movimento e ela tem sua própria cadência à qual estamos, por assim dizer, condenados."3 (STOPPARD, 1991[1967], p. 60).

Da sorte, da fortuna se pode esperar qualquer coisa e, no entanto, os dois ali experimentam em carne viva, ela pode surpreender! E,paradoxalmente,se surpreender com o mesmo. A cada lance da moeda as "leis de composição" dispostas foram dobradas, torcidas, esticadas até um limite impensável, impossível, real. E o sujeito ali, condenado. De antemão.

É nesse contexto que se passa o diálogo que Lacan destaca, servindo-se das três réplicas dos personagens para distinguir e mostrar "a distância que há" entre os três níveis da Mathesis (LACAN, 1967-1968 lição de 06/12/67), da apreensão científica/rigorosa (savante), designadas pelo termo greco-latino em questão. ${ }^{4}$ Partindo da distinção entre ler, escrever e perder como formas de conhecimento, esboçada por Lacan, buscaremos circunscrever a constituição do real e do sujeito em cada uma dessas vias da apreensão douta. Na direção deste esforço e mantendo no horizonte o reviramento efetuado sobre a noção de saber em sua articulação e aproveitamento no campo psicanalítico, procuraremos discernir de que modo a perda implicada necessariamente na práxis psicanalítica incidirá para o sujeito no nível de suas relações com o saber e com o ato.

O primeiro nível da mathesis Lacan centra num "eu leio", aproximando-o da teoria da reminiscência apresentada no Mênon (PLATÃO,427-347 a.C./1996). O segundo, distinto do primeiro e "presentificado no tom [...] do progresso de nossa ciência", Lacan (1967-1968, lição de 06/12/67) designa como "eu escrevo". Mas é num terceiro estamento, assinalado com um "eu perco" que Lacan considera que começa o que ao analista interessa mais de perto (LACAN, 1967-1968).

\section{Eu LEIO}

Quando "eu leio", "sou”, em princípio, um sujeito dado e "leio" um mundo já constituído fora de mim, como tal. Movo-me num espaço e tempo familiares, homogêneos, contínuos, extensivos (de dimensões finitas) e extrínsecos à minha existência (ou presença). Experimento um tempo que se desenrola linearmente do antes para o depois e um espaço que sendo plano e vazio pode conter todas as coisas. Mas se sou já constituído e há um mundo fora de mim, como posso chegar 
a conhecer o que não conheço? É esta questão colocada a Sócrates que dá lugar à exposição da teoria da reminiscência no Mênon de Platão. No Diálogo, Sócrates compara dois quadrados que existem na alma, no espírito do escravo. Um reto absoluto, contemplado outrora pela alma imortal e do qual lhe restam vestígios de memória - e o outro distorcido, - sombra do quadrado inteligível projetada no mundo sensível - são, ainda assim, decalques, um do outro. O escravo erra, ignora, não sabe "ainda". Mas pode saber.

No registro da reminiscência se supõe que tudo o que pode ser aprendido pode ser lembrado; que há já no espírito do homem (do escravo no caso do $M \hat{e}$ non) tudo o que pode responder ao que se coloca como questão para o saber. Não é necessário, absolutamente ,que se trate de quadrados idênticos, corretos. Mas mesmo quando se trata, de um lado, de um quadrado perfeitamente quadrado e do outro, algo de retorcido, não será menos a correspondência ponto a ponto (possibilidade de projeção do quadrado quadrado sobre o outro ou vice-versa) que organizará nossa apreensão. É isto o que confere um valor de "decifração" na relação de um sujeito com o que se apresenta no real.

Freud adotou esta posição nos primórdios da psicanálise ao tomar o lapso, por exemplo, como fenômeno elementar do inconsciente; ao perseguir nas manifestações do inconsciente a expressão evidente, irrecusável - "a ser lida" pode-se dizer -, de um pensamento estranho à consciência e no entanto plenamente organizado. Pensamento que incide e se diz; subvertendo os enunciados e fazendo a verdade cintilar brevemente, e depois ocultar-se. Lacan (1998[1953], p. 295) compara esta posição de Freud à de Champollion, que reabriu o acesso à leitura dos hieróglifos, mais de mil anos depois que o alfabeto egípcio tinha se perdido.

Freud e Champollion nos ensinaram que para ler é preciso, antes de tudo, supor que há texto e que o texto contém uma mensagem a que se pode aceder via leitura. Champollion demonstrou que a escrita hieroglífica não era meramente simbólica, icônica, apesar de ser composta de sinais facilmente reconhecíveis (como o abutre, a coruja, o olho, o pé) e outros, estilizados (como a forma amendoada para boca, a linha serrilhada para água etc.). Discernindo os cartuchos que se repetiam e atentando para seu lugar relativo nos textos grego, egípcio e demótico da Pedra de Roseta, Champollion pode conferir aos sinais da escrita hieroglífica valores de "ideogramas" - por exemplo, na utilização de uma vela inflada para representar o vento - e, mais que isso, de "fonogramas", ou seja: a utilização de coisas, ou, mais precisamente, suas imagens correspondentes, para representar "sons" e não as coisas mesmas - como no exemplo da boca, em egípcio, ro, utilizada para representar a consoante grega $\rho(r h o)$ (CHAMPOLLION, 1822, p. 11-12 apud ECO, 1995, p. 147-148). Supondo que cada incidência de uma mesma instância ou imagem representava o mesmo som, Champollion pode finalmente "ler" os nomes de Ptolomeu e Cleópatra ali onde outros só "viram" o abutre ou o touro, como ícones (representação de algo por direta similaridade).

À maneira de Champollion, Freud tomou os sonhos como "rebus". Restituiu as imagens do sonho ao registro fonético e, por esta via, decifrou o texto ininteligível da transferência. Como Sócrates no Mênon, ao constatar a defasagem que há 
entre as intenções do indivíduo e os achados do sujeito, Freud supõe que há de um lado a verdade expressa nos processos inconscientes, verdade que constituiria característica própria do locutor e que preexiste à sua articulação; e de outro, o lapso, por exemplo, mas também o sintoma ou o sonho, como circunstância que autoriza sua expressão. Na incitação à rememoração, presente nos primeiros movimentos freudianos, há a suposição da reminiscência: a suposição de algo imemorial, que existe e dura indefinidamente (as histéricas afinal sofriam de reminiscências) e se apresenta por meio das formações do inconsciente, justamente porque não se faz ato (o ato é falho aí). Para Freud tratava-se de decifrar o texto que o inconsciente é; de inferir e recolher o texto que o inconsciente produz, fora do registro da consciência. E ainda hoje, ao que parece, "o de que se trata no discurso analítico é sempre isso: o que se enuncia de significante, vocês dão sempre uma leitura outra que não o que significa" (LACAN, 1975[1972-1973)], p. 37).

Lacan indica que isso interessa aos analistas, na medida em que toda análise passa um pouco pela rememoração, pela colocação em série, em sucessão, de uma série de memórias ou asserções. A intervenção analítica opera por ligar de outra maneira uma sucessão determinada, revelando a existência de uma cadeia. Uma cadeia que é organizada pelo significante e não pelas intenções do falante, o qual só comparece aí fora do comando, representado. É justamente na medida em que isso chega a se evidenciar que a ação da interpretação pode se realizar (LACAN, 1967-1968). E lograr um certo deslocamento do sujeito; fazer o sujeito, paradoxalmente, "perder o fio" da meada, como veremos: "Qual é a sua primeira lembrança? [...] Devo tê-la esquecido".

$\mathrm{Na}$ análise, portanto, o sujeito lê suas lembranças e asserções, conferindolhes um sentido que se estabelece para além do código da língua e que será um sentido de desejo. E também o analista lê. "É evidente que no discurso analítico só se trata disso, do que se lê [...]" diz Lacan (1975[1972-1973], p. 29). O analista supõe o inconsciente como texto, e o sujeito do inconsciente, ele supõe que sabe ler e até que ele possa aprender a ler (LACAN, 1975[1972-1973)], p. 38), mas por outro lado, aquilo que ele pode ajudar o sujeito a ler não tem absolutamente nada a ver, em nenhum caso, com o que se pode escrever.

Quando eu leio o que o inconsciente dispõe, isso não está no almanaque. Não significa dizer que possuo um código que me possibilite explicar o lapso, o chiste... Por sua própria estrutura um lapso não pode ser explicado pois a perda que ele descortina e que caracteriza sua experiência não se pode escrever. Não há como de um lapso, fazer ciência, não há cartilha do que ali se lê. Pois dessa leitura é o sujeito que advém como efeito.

Além disso, se leio é porque o inconsciente já procedeu por interpretação e estou, portanto, como sujeito, em defasagem, barrado, impedido por relação a este saber que provêm do Outro. Se eu leio é porque aquilo que está no Outro, não me é facultado escrever e sim, ler - com toda a incompletude que isso implica e que abre o campo das interpretações. Ler é entrar em uma rede com mil entradas; é visar ao longe, não uma estrutura sólida de significado, uma lei de normas e desvios, mas uma perspectiva de restos, de vozes vindas de outros textos, de ou- 
tros códigos e cujo ponto de fuga é infinitamente aberto. Por isso as leituras são múltiplas, se infinitizam. Se chego a ter acesso a algum significado não é pelo que se apresenta - e muito menos pelo que se oferece imediatamente a meus ouvidos. "O significado", diz Lacan, "não é o que se ouve. O que se ouve é o significante". Ao pouco de significado a que podemos ter acesso se chega pela "leitura do que se ouve de significante" (LACAN, 1975[1972-1973], p. 34).

Nesse sentido, evocando o Mênon, Lacan diz que não há de fato quadrado (definido, delimitado) no espírito do escravo até que o desenho que lhe corresponde seja revelado numa operação. E de que operação se trata quando Sócrates interroga o escravo e lhe oferece no mesmo golpe seu quadrado? Lacan observa que o modo como Sócrates lhe traz o desenho do quadrado, a maneira pela qual ele raciocina e argumenta com o escravo é já dar ao escravo toda uma aula de geometria. Mas a questão não está aí. Se Sócrates traz um desenho e se há já, no espírito do escravo, tudo o que corresponde ao que Sócrates lhe traz, embora os dois quadrados não sejam de imediato idênticos, tratar-se-ia de metáfora? Isto é: não se vê este quadrado desenhado no espírito do escravo, mas bastaria iluminá-lo, expô-lo ao fogo, ou a algum procedimento químico, para que este desenho aparecesse, para que houvesse revelação (como se diz de uma placa sensível)? Estaria localizada entre estes dois polos a intervenção analítica? Um primeiro polo em que a interpretação, nosso desenho, vem "se aplicar sobre" a organização significante do inconsciente estruturado como uma linguagem; ou ao contrário, onde a interpretação seja da ordem da revelação de um desenho até então oculto? Não! Salienta Lacan.

$\mathrm{O}$ que torna as coisas mais difíceis para nós é que a análise concerne à operação do significante. E se a operação do significante permite e evoca a decifração, por um lado, o sujeito, por sua vez, não é algo plano como um desenho ou escrito com um texto. Ele está ele mesmo incluído na operação (como vimos a propósito de Freud e Champollion). Na operação significante o sujeito está incluído como "efeito" - determinado e inscrito como causado pelo significante (LACAN, 1967-1968, lição de 29/11/67). O resultado disso é que o saber que se adquire na operação da psicanálise será necessariamente falho. O saber falha, e são estes pontos de falha no saber que nos concernem como Verdade. Somos determinados nesta referência de tal modo que nos torna inaptos a resgatar ou recuperar o que se inscreve, como efeito significante, de nossa relação ao mundo. Inadequados à fecharmo-nos, à completarmo-nos de forma satisfatória no plano do saber. E esses pontos que não chegamos a fechar, a cerzir, satisfatoriamente, nos atravessam quando somos chamados a posicionarmo-nos como sexuados, em perene abertura para o Outro.

Pela mesma razão vem aí se instalar o sujeito suposto saber, com o que visamos derrogar o que não é suposto, o que resiste à operação do saber, fazendo sujeito, ou seja, a verdade. É, então, nessas brechas, na suspensão do encadeamento automático produzido pelo saber, que nos localizamos enquanto sujeitos. É na falha do saber que se situa o sujeito, no lugar em que o saber se completa não há espaço para o sujeito. Por aí se pode aquilatar o que a operação da ciência tende a eliminar (como veremos), e ao mesmo tempo, se pode discernir como tal 
manobra se distancia da análise, cuja operação consistirá em aguardar e, eventualmente, produzir a falha no saber por onde emerge a Verdade no discurso de um sujeito que não pode ser ensinado.

\section{Eu ESCREVo}

A segunda forma de constituição de conhecimento e do mundo que está presente para o sujeito e também na psicanálise, Lacan define como "Eu escrevo". E adverte que não se trata aqui simplesmente da escrita como registro da memória, ou da escrita que é instrumento para comunicação de palavras ou idéias, presente historicamente nas sociedades humanas e sim da escrita que dá "o tom de progresso de nossa ciência [e de cuja presença, o]destacamento da incidência significante" é fruto (LACAN, 1967-1968, lição de 06/12/67).

Costumamos pensar sobre a escrita em termos romanceados. Acreditamos que a invenção dos primeiros sinais escritos deve ter respondido a anseios de perpetuação da presença do homem, de suas lendas e costumes. Todavia, se sabe hoje, efetivamente, que os primórdios da história da escrita - da escrita propriamente dita, a qual se destaca dos inúmeros meios mais ou menos sistematizados de transmitir mensagens por meio de desenhos, sinais, imagens existentes há dezenas de milhares de anos - estão ligados ao registro de contas agrícolas e notas de compra e venda, num contexto de disparidade de línguas (JEAN, 2002[1987], p. 12-19). As chamadas "plaquetas de Uruk", as primeiras notações descobertas na região da Suméria, continham listas, relações, de sacos de grãos, de cabeças de gado, estabelecendo uma espécie de contabilidade do grande templo da cidade de Uruk. Outras plaquetas da mesma época registram a organização social dos sumerianos e informam que a comunidade religiosa do templo de Lagash empregava 18 padeiros, 31 cervejeiros, 7 escravos, 1 ferreiro etc. E testemunham também o fato de que os sumerianos inventaram não somente a moeda, mas também o empréstimo e o crédito (JEAN, 2002, p. 13-14). É verdade que na esteira dessa escrita "cuneiforme" constituída por um sistema complexo de pictogramas, nasceram e se desenvolveram os sistemas de escrita fonéticos (segundo Jean, a partir de cerca de 2900 a.C.) que vieram mais tarde possibilitar a fixação de códigos jurídicos, tratados científicos, narrativas e obras literárias, como as conhecemos hoje. Não obstante é notável que a invenção e presença da escrita não possa ser dissociada dos calculi - as pedrinhas que continham inscrições geométricas utilizadas para "contar", "calcular".

Hoje, a escrita está presente em nossas vidas de inúmeras maneiras, que ultrapassam muito o âmbito do registro. Nosso mundo hoje é povoado por gadgets que são concretizações do saber formalizado, articulado cientificamente. Objetos inteiramente tributários da escrita, que nenhum processo "antigo" de fabricação, orientado simplesmente pelas práticas e valores da cultura, teria sido capaz de produzir (LACAN, 1991[1969-1970], p. 184).

Lacan observa que o destacamento da função do significante como tal é fruto da escrita da ciência, enfatizando o que foi assinalado por diversos autores (por exemplo, KOYRÉ, 1998[1962]; KUHN, 1998[1970]) a propósito da mate- 
matização que deu origem à ciência moderna. A formalização do real operada pela ciência implicou uma radical alteração de toda nossa relação à linguagem - e não apenas, como se costuma pensar, a substituição de uma linguagem antiga (linguagem da natureza ou aristotélica) por outra (a linguagem dos caracteres matemáticos de Galileu). Até o advento da ciência moderna, como diz Koyré (1998[1962]) o mundo era fechado e ordenado pelo sentido. Mas para que a ciência transpusesse os limites do mundo fechado nos confrontando ao universo infinito da precisão, foi necessário que a matematização pudesse ordenar o real, fazendo a natureza aparecer escrita em caracteres matemáticos. Ora, a matematização não trouxe consigo somente a inteligibilidade. Expulsando do real todo dado sensível, toda diversidade que seja irredutível como tal, a matematização estabelece, por sua rede, um real que prescinde da semântica e cujos problemas e impasses - longe de convocarem o ato do sujeito para seu desdobramento - podem ser remetidos ao jogo sintático próprio ao cálculo e da escrita.

O jogo da escrita, Lacan nos apresentou desde seu "Seminário sobre a carta roubada" (LACAN, 1998[1957a]) como um jogo que não deve sua justeza ou exatidão senão ao respeito por certo número de regras formais, que independem do conteúdo dos enunciados em questão e também de qualquer enunciação, possibilitando, portanto, equacionamentos independentes das diferenças qualitativas (sensíveis) envolvidas (HENRY, 1998). Tal é o sentido mais agudo da indicação de Lacan de que a ciência libera no mundo significantes que se organizam, que respondem a leis, sem estarem relacionados a um sujeito ou a uma essência que se expressaria por seu intermédio. Paradoxalmente, trata-se do mesmo significante que, exatamente por seu jogo literal - no qual a letra se presta para suportar todas as significações - constitui o que Lacan (1998[1957b], p. 496 e segs.) nomeou a "instância da letra" - a qual Freud encontrou compondo o sonho e constituindo o sintoma em sua equivocidade, e cuja função de representação do sujeito ele restituiu no campo psicanalítico.

Lacan reflete sobre isso sistematicamente, desde o seminário $A$ identificação (LACAN, 1961-1962), quando se esforça por caracterizar a lógica do significante demarcando-a da lógica clássica e tenta extrair as implicações que o advento da ciência formal matematizada introduz para a sustentação da presença do sujeito no campo do discurso (FERNANDES; COSTA-MOURA, 2009). A tese de Lacan é conhecida. Para ele, o sujeito é um precipitado produzido (forcluído) pela operação da ciência (LACAN, 1965-1966 - lição de 01/06/66).

O sujeito que daí resulta, independendo de qualquer atributo intrínseco, "acontece" no "sistema espaço-tempo" . Habita o espaço e tempo relativos, multidimensionais, intrínsecos à escrita da ciência e apensos à sua operação. Tempo e espaço, aqui não são mais planos, nem familiares e nem sequer físicos. Trata-se de espaço matemático e matematizado, medido por valores de velocidade e não pela métrica. Se caminho ,por exemplo, sobre uma faixa de Moëbius (e sabemos que fazemos esta experiência constantemente na vida, embora ela não cesse de nos surpreender), tenho uma experiência e apreensão do espaço (e do tempo) 
muito diferente daquela que teria, andando sobre o plano, uma esfera, ou ainda pelo cross-cap. Se na terra peso $60 \mathrm{~kg}$, e tenho 20 anos, em Mercúrio eu teria 22 $\mathrm{kg}$ e 83 anos, em Júpiter 122 quilos e apenas 20 meses etc.

Desamarrado do Cosmos e reduzido ao Cogito, sem saber nem extensão permanentes; descolado das representações que lhe conferiam um lugar estável e lhe asseguravam estabilidade e consistência; sem lugar social definido e sem poder contar nem com sua corporeidade como intrínseca (coisa que a tecnologia médica, por exemplo, tratou de modificar), o sujeito da ciência desencarnou. Impossibilitado de se reconhecer em seu ato - que lhe vem sombreado pelo pathos, ou pela patologia - e não podendo referenciar suas ações num conjunto de valores dados, é capaz de proezas, mas pisa em falso. E tem, doravante, nas palavras de Lacan (1975[1974]) a maior dificuldade de "pensar com os pés", uma vez que, para advir como sujeitos, perdemos a natureza (a inocência) que poderia nos conferir alguma imanência.

Colhidos agora no jogo da escrita - que governa nossos corpos e extrai de nós nossos números (desde documentos e registros até nossas contas bancárias e medições de saúde), "jogados" que somos em nossos indefectíveis aparelhinhos: celulares que "escrevem" por nós, antes de nós; websites que "sabem" antes de nós o que pode nos interessar comprar, o que pode nos convir fazer etc. - calculamos. E estamos, como constata o personagem de Stoppard (1991[1967]), condenados a calcular.

\section{Quem SABia?}

$\mathrm{Na} 1^{\mathrm{a}}$ lição do mesmo seminário em que distingue as mathesis, cotejando a psicanálise com o modo da ciência se produzir em torno da letra e da escritura, Lacan (1967-1968) leva em consideração a demonstração de Cantor da existência do número real. E diz:

[Observe-se] como procede Cantor para demonstrar que a dimensão do transfinito nos números não é absolutamente redutível àquela da infinidade dos números inteiros, à saber, que se pode sempre fabricar um novo número que não terá sido incluído de princípio nesta série de números inteiros. Tão espantoso quanto isto possa parecer a vocês, [a demonstração de Cantor não é] nada senão uma certa maneira de operar com a série dos números segundo um método que se chama diagonal. (LACAN, 1967-1968, lição de 15/11/67)

A indicação de Lacan parece apontar, em primeira instância, para uma tematização mais estreita em torno da ciência e seus conceitos operatórios, notadamente a matemática e sua fundamentação na letra. E, como sempre, se Lacan aproxima a análise da operação da ciência não é tanto para insistir na cientificidade da psicanálise, mas para determinar de que modo a psicanálise é um efeito da ciência e quais são suas responsabilidades neste mundo marcado pela presença desta. 
Aqui, porém, quando introduz Cantor, Lacan ressalta o que a escrita implica de suporte à prova de Cantor para a demonstração de que os números reais não são "contavelmente" infinitos (ou, equivalentemente, não formam um conjunto infinito "enumerável"). A demonstração em questão envolve o problema do infinito. E, notadamente, o chamado infinito atual, ou seja, o infinito atualizado, presente. Um "infinito" que pode ser concebido como uma entidade "completa", "acabada"; no qual todos os elementos podem ser pensados num ato único, como já dados à nossa percepção (ainda que não possamos "visualizá-los" simultaneamente). Cantor nos mostra que o infinito está atualizado no jogo fundamental da escrita implicado na sequenciação dos números, mas isso não quer dizer que o entendamos, que possamos contá-lo, enumerá-lo, absorvê-lo ao Saber. E, no entanto, eu posso escrevêlo (por exemplo, na disposição dos números segundo o método da Diagonal) e a partir do momento em que "eu escrevo" este objeto que eu não conheço, eu o faço entrar numa série de efeitos e operações por meio das quais eu posso, inclusive, chegar a uma ordem de coisas completamente inacessível de outro modo.

O que está do cerne no esquema demonstrativo de Cantor (e também no teorema de Gödel), é justamente o fato da enumeração exaustiva, unívoca, não só não saturar seu campo extensivo, como produzir aquilo que o excederá - desde sempre (NAGEL; NEWMAN, [1973]). O que a demonstração de Cantor realiza é a evidenciação, ao nível da letra, de que algo "vaza", "escapa", "fura" a possibilidade de sutura que letra e escrita operam. Prova de que as "leis de composição", prescrevendo as possibilidades do que se pode saber, não se instituem sem trazer consigo aquilo que "ex-siste" ao próprio significante, vale dizer: o real e o sujeito. A propósito disso, Lacan evoca Cantor e, a partir dele, a evidenciação da escrita como "atividade" a partir da qual o real pode se por.

Sobretudo, trata-se, para Lacan, de localizar, no significante, agora reduzido ao mínimo de uma combinatória, o suporte de um tipo de apreensão, de constituição do real que só podia ser esboçado palidamente numa ordem discursiva apensa à dimensão do sentido (como a filosofia ou a linguagem ordinária, por exemplo). Assim, nos mostra que, para situar o real, é necessário a letra: "se existe uma chance de captar algo que se chama o real, não é em outro lugar senão no quadro negro" (LACAN, 1991[1969-70], p.176). Não se chega ao real nem pelo reducionismo biofísico (que afinal limparia o real, da impureza que é o sujeito e seus móveis sexuais), nem pelo apelo ao transcendental (pois afinal a ciência mais do que qualquer outra formação discursiva já tratou de derrogar o pai que suportaria o transcendental). Em nossa condição de sujeito estamos limitados a acessar o real pela via colocada em marcha pela própria ciência - ordem dos significantes, que funcionam independentes do saber que podemos tecer sobre eles. E por outro lado, a letra, a combinatória é suficiente para marcar este aspecto do real que não é nem aquém, nem além; que é fundamentalmente presença da estrutura.

Porém, se a noção de real introduzida por Lacan tem como origem este real que a ciência demarca - real esvaziado de sentido, reduzido ao mínimo que se produz pela formalização e, sobretudo, nos impasses da formalização - é preciso que se diga que aí estamos longe, ainda, da incidência do real para o sujeito. O real que 
é também definido por Lacan, por meio de uma das categorias da lógica modal, como impossível. Impossível que nos acossa e emerge, aqui e ali, derrogando nossa pretensão cientificista, de tudo regular. Impossível tomado não mais como em Aristóteles (como aquilo que não pode ser), mas sim como "o impossível é o real". Aquilo que "não cessa de não se escrever" (LACAN,1975[1972-1973], p. 55) e que é o correlato antinômico e necessário do que a ciência escreve como regularidades; do que "não cessa de se escrever" (LACAN,1975[1972-1973], p. 55).

Por isso mesmo, de forma alguma podemos confundir o domínio em que a ciência opera, com o simbólico tal como o entenderemos a partir de Lacan. Tratase, antes, daquilo que Lacan (1975[1972-1973], p. 29) nomeia como "função do escrito"- e que perfaz um real que "ex-siste" ao mundo. Vale dizer: um real que não permite nem articulação, nem mobilidade, nem unidade, nem sentido.

Levando isso em conta, depois de evocar a diagonal, Lacan coloca a pergunta:

“[...] a abertura desta ordem seguramente controlável e que tem o direito [...] à qualificação de verídica, é o caso que esta ordem estivesse lá, esperando a operação de Cantor desde sempre? (LACAN, 1967-1968, lição de 15/11/67).

E Lacan nos adverte que esta é uma questão que tem valor; que não se reduz àquela da anterioridade da realidade por relação à representação, pois no caso da diagonal de cantor trata-se de saber como, de uma escrita, de uma combinatória que poderíamos, sem exagero, dizer "cega", pode se desdobrar uma dimensão de verdade, a mais autêntica - uma vez que ela comparece ali antes mesmo de qualquer saber.

É uma pergunta surpreendente. Aí se vê Lacan às voltas com esta problemática do vazio e da perda enquanto afeitas ao registro do real, em termos daquilo que estaria lá "antes" ou "a parte" do saber, ou, o que é de algum modo equivalente, de um sujeito suposto saber. Como, sem cair num empiricismo ou realismo ingênuo, colocar a questão sobre o real em cesura com o saber? Como evocar o que estaria lá (lá onde?) desde sempre? Antes que o soubessem. É neste contexto que Lacan vai situar a escrita. Ele não requisita uma entidade heterogênea à linguagem como "fora-da-linguagem" que pudesse dar conta do real que a suporta. Para Lacan, o vazio e a perda que assinalam o real são cavados no próprio jogo da escrita. Esta fundamentação no jogo da letra libera a psicanálise da ontologia e situa a realização da subjetividade no campo da linguagem. E é em razão dessa dependência do real face ao jogo da escritura e do efeito sujeito que aparece nesta conjuntura (entre real e escrito) que a questão da psicanálise permanece referida à ética. Pois, a rigor, o sujeito se realiza justamente na assunção em ato de sua determinação, como efeito de escrita; como lei de composição que o institui como real - na medida mesmo em que sua substância, propriamente dita, "não cessa de não se escrever” (FERNANDES; COSTA-MOURA, 2010, no prelo). 


\section{Eu PERCo}

A apreensão mais própria da psicanálise, diz Lacan (1967-1968, lição de 06/12/67), começa num "eu perco". Se as três réplicas designam os modos próprios de constituição de conhecimento que são os do sujeito; "eu perco", e especialmente, "eu perco o fio", remete os analistas a uma referência essencial: "o que entrou no mundo com os primeiros passos da análise", a saber, o campo do lapso, do tropeço, do ato falho (LACAN, 1967-1968, lição de 06/12/67). Daí a psicanálise parte: há outra verdade, diferente da intenção. Uma verdade que somente se divisa em perda (perda de saber, de arrogância, de inocência, de gozo).

Não bastasse a surpresa dessa afirmação de que há um nível da mathesis que se passa no plano de um "eu perco", e mesmo, de que há um nível da mathesis que se passa exclusivamente nesta referência, Lacan ressalta ainda que aí está o que é mais próprio da psicanálise e mesmo, o que constitui uma "base" (!) de onde partir, sem a qual não haveria nem mesmo análise possível (LACAN, 1967-1968, lição de 06/12/67).

Em 1964, num momento de virada de seu seminário, enquanto se empenhava em levar os psicanalistas, dos conceitos freudianos ao objeto da psicanálise, Lacan já tinha definido a psicanálise como "um campo que por sua natureza se perde" (LACAN, 1985[1964], p.122). Diferente das passadas de um Newton, um Einstein, um Planck, dizia ele, o campo que Freud inaugurou, "traçando no real um sulco novo" (LACAN, 1985[1964], 122), é um campo que se perde; que não se sustenta por si só, sem o passo ético do sujeito (caído do lapso, ou do sintoma que o presentificou) que deve tomar lugar aí. E Lacan (1985[1964]) adverte-nos já ali, que se trata de uma "perda seca" que nenhum ganho vem saldar. O analista, diz ele (LACAN, 1985[1964]), é testemunha desta perda. É aí que ele encontra sua função irredutível.

Se a ciência chega a um impossível, como vimos, este não é ainda um impossível que concerne ao sujeito. Trata-se de um impossível para a letra, a partir do qual não se atinge imediatamente o que está em jogo quanto ao "eu perco". "Eu perco" porque a escrita não escreve tudo (há o que não cessa de não se escrever). E só um sujeito perde. "Eu perco" e neste corte algo se diz para além de tudo o que se pode escrever.

Nesse sentido, testemunhar a perda a seco, em abstinência, como dizia Freud (1976[1914-1915]) talvez seja o ato do psicanalista. Enquanto o sujeito escamoteia a perda e ordena o que cai a partir de um olhar que é sempre tirânico, o artista ,por exemplo, pode capturar o vazio que a perda significante engendra e fazer disso matéria para criação (LACAN, 1986[1959-1960]). Quanto ao analista o que lhe cabe talvez seja o ato em perda.

É a propósito do ato sintomático que se fará o reviramento a meu ver mais desconcertante do seminário sobre o ato psicanalítico. Retomando as análises sobre erros e atos sintomáticos na "Psicopatologia da vida cotidiana" de Freud (1976[1901]), p. 263) Lacan (1967-1968, lição de 22/11/67) deixa indicado que mais que veicular um sentido oculto ou intenção inconsciente, a importância dos 
atos sintomáticos -, sejam eles caracterizados pelos lapsos de palavras ou ainda neste registro da ação cotidiana onde se encontram os erros, os equívocos, as ações malogradas (Vergreifung) -, reside no fato de que, uma vez que a intervenção analítica tenha demarcado em cada um deles sua dimensão de ato (retirandoos da esfera da ação e da motricidade, nas quais se abrigavam), este ato vai luzir seu sentido precisamente sobre o que se trata de atacar, de abalar, ou seja: a nossa convicção num sentido para nossos atos, resguardado da falha e da equivocação.

Mostrar o ato ali onde havia a falha, a psicopatologia, o sintoma, este foi o estatuto novo e mesmo inaudito que Freud conferiu ao ato. Para Lacan, este estatuto nos atinge no cerne narcísico que ele chama a nossa "babaquice" (connerie). A babaquice, diz Lacan (1967-68, lição de 22/11/67), não é uma noção, é antes um nó. O nó que é o nosso núcleo duro, em torno do que giramos e construímos nosso mundo alimentado pelo desconhecimento. Há sempre um ponto cego a partir do qual tudo o que se elabora de saber se constitui para o sujeito. Este ponto nos fornece uma certeza, à qual nos fixamos e identificamos. E nessa certeza nos sustentamos. $\mathrm{O}$ ato sintomático nos surpreende justamente porque desarticula a certeza que nos sustenta. Pois o que deixa ver e transmite é o que aí se apresenta de nossa forma própria de desconhecimento e de queda, onde só podemos reco$n$ hecer nossa babaquice (nosso ponto de gozo).

Neste sentido o que há de mais original na análise freudiana do ato sintomático é o que esta análise produz de abertura - "traço de luz inundante e que por muito tempo não voltará a se fechar" (LACAN 1967-1968, lição de 22/11/67) - abertura ao que Lacan volta a evocar neste ponto como uma "subversão do sujeito".

Esta é, então, a natureza da mensagem que Freud (1976[1901]) ressalta, ao atribuí-la a si mesmo e ao mesmo tempo aferrar-se em dizer que ela é de todo desconhecida. O que jaz afinal neste "estranho registro" (LACAN, 1967-1968, lição de 22/11/67) não pode ser retomado senão decaindo de seu próprio nível. O que interessa no lapso, muito mais que seu conteúdo de verdade (às vezes confessional) é a verdade Outra que ele veicula. É sua dimensão de corte que nos expõe a nós mesmos, sem perdão. Corte com o "mesmo" que somos; corte que expõe a presença de um sujeito ativo ignorado pelo falante. Um sujeito que apareceu com a própria locução e se eclipsou logo que a letra veio manifestá-lo. Este sujeito, animado por um desejo, testemunha "em perda" algo além de mim que pensa em meu lugar. E se dá a ouvir, operando, antes que eu possa saber, antes que eu possa dizer "eu sou". "Eu não sou", "eu perco": eis-me diante de minha condição de sujeito.

Talvez se possa dizer do lapso, algo análogo ao que Lacan isola como estando na base do ato psicanalítico a saber: quando "eu perco", resulta daí, ainda que brevemente, alguma coisa como "uma conversão da posição do sujeito quanto a sua relação com o saber" (LACAN, 1967-1968, lição de 22/11/67). Se a babaquice é o nosso núcleo duro, o lapso, a queda do sujeito é o corte que vem lancetá-la. Sim, porque a nossa babaquice nós não a deixamos de bom grado. Só quando caio, só em perda, experimento o que de fato me constitui e que eu trabalho ativa e incessantemente para desconhecer. Isso dói. 
Da perda que experimento quando caio como sujeito - quando caio de minhas convicções, de minhas boas intenções, de meu narcisismo - não resulta nenhum saber, essa é a experiência da análise. Não se pode calcular a perda. Não se pode programá-la, nem evitá-la, nem otimizá-la. Entra-se, aí, não se sabe como, entra-se mesmo sem pensar e está-se aí sem saber. O que resulta disso pode ser, na melhor das hipóteses, esta já mencionada "conversão da posição do sujeito por relação ao saber": não se trata de saber; trata-se de ato. Quando perco não acedo; caio. Tomo lugar naquilo que eu "não sei" quando estou "achado". Esse é o espaço que habito, no tempo de meu ato.

Se enquanto "eu leio", frequento um tempo e um espaço dados de antemão, pacificados, extrínsecos; e se na medida em que "eu escrevo" constituo um espaço-tempo animado, mutável, intrínseco a esta escrita mesma, na perda a topologia é outra. Não há exterior; nem interior, não há orientação possível. Tudo é turbilhão e pulsa arrítmico. Trata-se do espaço definido pela "Outra cena" e do tempo definido pelo ato.

Lacan designa isso como verdade. $\mathrm{O}$ ato, quando sobrevém, nasce dessa perda que é a verdade para nós: ler, escrever..., perder o fio.

\section{Notas}

${ }^{1}$ No original: Guil: "What's the first thing you remember?/ Ros - Oh lets see... The first thing that comes into my head, you mean? / Guil: No; the first thing you remember / Ros: Ah. (Pause) No, it's no good, it's gone. It was a long time ago/ Guil (patient but edged): you don't get my meaning. What is the first thing after all the things you've forgotten?/ Ros: Oh I see. (Pause) I've forgotten the question. (STOPPARD, 1967/1991, p. 16). A peça do dramaturgo inglês, Tom Stoppard, estreou no Festival de Edimburgo em 1966 com grande sucesso e em Nova Iorque em 1967. Em 1990 foi transformada em filme roteirizado e dirigido pelo próprio Stoppard.

${ }^{2}$ No original "whatever became of the moment when one first knew about death? There must have been one, a moment, in childhood, when it first occurred to you that you don't go on forever. It must have been shattering, stamped into one's memory. And yet I can't remember it."

${ }^{3}$ No original: "Wheels have been set in motion, and they have their own pace, to which we are... condemned"

${ }^{4}$ Segundo o registro do dicionário BAILLY (grego-francês) Máthesis : "ação de aprender", de "se instruir", mas também, "desejo de se instruir" e, além disso, "conhecimento", "instrução", "ciência". Máthesis é também o "matemático", no sentido grego desta palavra (tá mathémata), ou seja, o que se pode aprender e o que se pode ensinar. Esse aprender que está em jogo no sentido grego de "matemático", de Máthesis, é tomar conhecimento de algo que já sabemos de modo antecipado. A teoria da reminiscência diz respeito a esse sentido originário de Máthesis. O matemático como o campo do numérico, que é o matemático no modo como o entendemos, é um sentido tardio da palavra grega Máthesis. Parece ser essa a outra possibilidade de Máthesis à qual Lacan se refere, dizendo que está "presentificada no tom do progresso de nossa ciência" (BAILLY, 2007).

${ }^{5} \mathrm{Na}$ física pós relatividade, espaço-tempo é um sistema de coordenadas composto pela articulação entre o tempo e o espaço tridimensional concebidos, em conjunto, como uma única variedade de quatro dimensões. Um ponto, no sistema espaço-tempo, pode ser designado como um "acontecimento". Cada acontecimento tem quatro coordenadas (t, l, h, p; ou, em coordenadas angulares, $\mathrm{t}, \mathrm{r}, \theta$, e $\varphi$ ), que dizem o local e a hora em que tal evento ocorreu, ocorre ou ocorrerá. Aqui exploramos as consequências para o sujeito de habitar um espaço em que, diferente do espaço plano da geometria euclidiana, dado um determinado ponto, ou bem não se pode traçar nenhuma paralela a ele (espaço esférico) ou se pode traçar infinitas paralelas (espaço hiperbólico). 


\section{REFERÊNCIAS}

BAILLY, M. A. Abrégé du dictionnaire grec-français. Paris : Hachette, 2007.

CHAMPOLLION, J. F. Lettre à M. Dacier relative à l'alphabet des hiéroglyphos phonétiques. [S.1.: s.n.], 1822.

ECO, U. The search for the perfect language. Oxford: Blackwell, 1995.

FERNANDES,F. L.; COSTA-MOURA, F. Lógica da ciência, formalismo e forclusão do sujeito. In: COSTA-MOURA, F. (Org.). Psicanálise e laço social. Rio de Janeiro: 7 Letras, 2009. p. 144-166

FERNANDES, F. L.; COSTA-MOURA, F. Quem sabia? O escrito como fundamento em ato do real. In: C. OLIVEIRA (Org.). ENCONTRO DE PESQUISADORES EM PSICANÁLISE E FILOSOFIA, 3., 2010. Rio de Janeiro. Anais... Rio de Janeiro: s.n., 2010. No prelo.

FREUD, S. Observações sobre o amor transferencial (1914-1915). In:

Obras Psicológicas Completas de Sigmund Freud. Rio de Janeiro: Imago. 1976. v. XII, p. 208-221. Edição Standard Brasileira.

FREUD, S. A psicopatologia da vida cotidiana (1901). In: . Obras Psicológicas Completas de Sigmund Freud. Rio de Janeiro: Imago, 1976. v. VI, Edição Standard Brasileira.

HENRY, J. A revolução científica e as origens da ciência moderna. Rio de Janeiro: J. Zahar, 1998.

JEAN, G. A escrita: memória dos homens (1987). Rio de Janeiro: Objetiva, 2002.

KOYRÉ, A. Du monde clos à l'univers infini (1962). Paris: Gallimard, 1998.

KUHN, T. A estrutura das revoluções cientificas (1970). São Paulo: Perspectiva, 1998.

LACAN, J. Função e campo da fala e da linguagem em psicanálise. In:

Escritos (1953). Rio de Janeiro: J. Zahar, 1998, p. 238-324.

LACAN, J. Seminário sobre A carta roubada (1957a). In: Écrits. Rio de Janeiro: J. Zahar, 1998. p. 11-66.

LACAN, J. A instância da letra no inconsciente ou a razão desde Freud (1957b). In: . Écrits. Rio de Janeiro: J. Zahar, 1998. p. 496-537. 
Fernanda Costa-Moura

LACAN, J. Le seminaire: 1' éthique de la psychanalise (1959-1960). Paris: Seuil: 1986. Livre 7.

LACAN, J. L'Identification. [S.1.: s.n.], 1961-1962. Seminário inédito.

LACAN, J. O seminário: os quatro conceitos fundamentais da psicanálise (1964). Rio de Janeiro: J. Zahar, 1985. Livro 11.

LACAN, J. L'objet de la psychanalyse. [S.1.: s.n.], 1965-1966. Seminário inédito.

LACAN, J. L'Acte psychanalytique. [S.1.: s.n.], 1967-1968. Seminário inédito.

LACAN,J. Le Séminaire: 1'envers de la psychanalyse (1969-1970). Paris: Seuil, 1991. Livre 17.

LACAN, J. Le Séminaire: encore (1972-1973). Paris: Seuil, 1975. Livre 20.

LACAN, J. La troisième (1974). Lettres de L'École Freudienne de Paris, Paris, n. 16, p. 177-203. 1975. 7e Congrès de l'École Freudienne de Paris.

NAGEL, E.; NEWMAN, J. A prova de Göedel. São Paulo: Perspectiva, [1973].

PLATÃO. Diálogos I: Mênon, Banquete, Fedro. Tradução de Jorge Paleikat. Rio de Janeiro: Ediouro, 1996.

SHAKESPEARE, W. Hamlet: Prince of Denmark (1599-1601). Oxford: OUP, 1992.

STOPPARD, T. Rosencrantz \& Guildenstern are dead (1967). New York: Grove Press, 1991.

Recebido em: abril de 2010

Aceito em: junho de 2010 